\title{
Dar Zarrouk Parameter as a Tool for Evaluation of Well Locations in Afikpo and Ohaozara, Southeastern Nigeria
}

\author{
Robert Egwu Otu Iduma ${ }^{1}$, Tamunoene Kingdom Simeon Abam², Etim Daniel Uko ${ }^{3}$ \\ ${ }^{1}$ Groundscan Services Nig. Ltd., Port Harcourt, Nigeria \\ ${ }^{2}$ Institute of Geosciences and Space technology, Rivers State University of Science and Technology, \\ Port Harcourt, Nigeria \\ ${ }^{3}$ Department of Physics, Rivers State University of Science and Technology, Port Harcourt, Nigeria

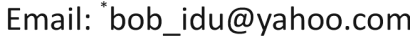

Received 1 December 2015; accepted 26 April 2016; published 29 April 2016

Copyright (C) 2016 by authors and Scientific Research Publishing Inc.

This work is licensed under the Creative Commons Attribution International License (CC BY).

http://creativecommons.org/licenses/by/4.0/

c) (i) Open Access

\section{Abstract}

The inhabitants of this area depend solely on contact springs as supply source of potable water. However, provision of potable water to meet the needs of the people still remains an unsolved problem. Therefore, this paper attempts to solve this problem by using Dar Zarrouk (D-Z) Parameters; Total Transverse Unit Resistance, $T\left(\Omega \mathrm{m}^{2}\right)$ and Total Longitudinal Unit Conductance, $S\left(\Omega^{-1}\right)$ to suggest optimal locations for drilling of boreholes in the study area. To attain this purpose, 50 Schlumberger Vertical Electrical Sounding (VES) curves with maximum current electrode spacing of $A B / 2=681 \mathrm{~m}$ were interpreted. Thus, the aquifer parameters information estimated from the (VES) curves were used to prepare contour maps of $T\left(\Omega \mathrm{m}^{2}\right), S\left(\Omega^{-1}\right)$, aquifer thickness $h(m)$, aquifer resistivity $\rho(\Omega \mathrm{m})$, and Water Table Depth (WTD). For effective use of these parameters, iso-thickness and iso-resistivity maps were compared with contour map of transverse resistance. The good agreement between these parameters provided the basis for identification of prolific aquiferous zones. It was observed that the Southern part of the study area majorly underlain by the Afikpo Sandstone of Nkporo Formation (Campanian-Maastrichtian), relatively showed higher $T\left(\Omega \mathrm{m}^{2}\right), h(\mathrm{~m})$, and $\rho(\Omega \mathrm{m})$ values, which implies high yield aquiferous zones. The relatively loose structure of this sandstone unit, coarse grains, and sorting enables it to be porous and permeable. The Northern part of the region which shows low values for $T\left(\Omega \mathrm{m}^{2}\right), h(\mathrm{~m})$, and $\rho(\Omega \mathrm{m})$ suggests low productivity for the aquiferous zones. The paucity of water in this parts of the study area can be explained to be as a result of the dominant geology. The high $S$, values at the Uburu and Okposi

\footnotetext{
${ }^{*}$ Corresponding author.
} 
locations in this region suggests the presence of saline aquifer. This study would be relevant to the development of effective ground water scheme and for future hydrogeological investigations in the area.

\section{Keywords}

\section{Vertical Electrical Sounding, Dar Zarrouk Parameters, Nkporo Formation, Afikpo Sandstone}

\section{Introduction}

The continuous growth of population and development projects in the area has contributed to the indiscriminate existence of failed boreholes and dry wells which pose great concern to the people of the region. Some wells are, most often, susceptible to drought especially in dry weather conditions (dry season); many others go dry soon after well completion, while some do not show any sign of water presence even after drilling at greater depths. This challenge of groundwater supply could be attributed to the difficulty in visualizing the occurrence and movement of groundwater by water borehole drillers in the area, since groundwater is normally hidden from view. As a consequence, this complexity adversely affects the ability to understand and to deal effectively with groundwater related problems. To remedy this situation, a precise and detailed geophysical study becomes critical in order to elucidate the behavior of groundwater aquifer in the area. Aquifer Transmissivity $\left(\mathrm{m}^{2} \cdot \mathrm{d}^{-1}\right)$, hydraulic conductivity $\left(\mathrm{md}^{-1}\right)$, aquifer thickness $(\mathrm{m})$, Transverse Resistance $\left(\Omega \mathrm{m}^{2}\right)$, Longitudinal Conductance $\left(\Omega^{-1}\right)$, and Storage Coefficient are the common fundamental properties usually studied [1]. Thus, the aim of this study is to use Dar Zarrouk parameters; Transverse Resistance $\left(\Omega \mathrm{m}^{2}\right)$, and Longitudinal Conductance $\left(\Omega^{-1}\right)$ to estimate optimal well locations.

Geophysical methods are methods that use the physical properties of earth materials to interpret subsurface structure. The electrical resistivity value of geological formations depends on the lithological properties (density, porosity, pore size and shape), and water content and its quality and temperature [2]. DC-resistivity measurements can contribute significantly to enhance the correctness of the groundwater model by delineating aquiferous zones, using the established relationship between geoelectrical and hydrogeological parameters. [3] estimated the distribution of aquifer hydraulic parameters in the Southern part of Akwa Ibom State, Southern Nigeria using surfacial geophysical measurements. Based on the transmissivity and transverse resistance maps, they were able to identify zones where the aquifer was productive. [4] exploited Dar Zarrouk (D-Z) parameters to differentiate between fresh and saline groundwater aquifers of Sinjar Plain area and the results showed that the distribution of the D-Z parameters and other geoelectric parameters gave insight into the occurrence and distribution of saline and fresh water aquifers in the study area. In an attempt to estimate hydrogeophysical parameters for aquifer characterization in hard rock environment, Yaounde, Cameroon, [5], carried out a detailed local geological and hydrogeophysical investigations for the aquifer in Yaounde, Cameroon to delineate the architecture of different subsurface geological horizons using lithologs and generated vertical electrical sounding (VES) data. The results showed a direct relation between aquifer transmissivity and transverse resistance. Surface direct measurements have been used by many other workers to estimate the hydraulic properties of aquifers [6][11]. Their results indicate that the DC resistivity method does provide a fast, economic and non destructive way to study aquifers. Therefore, the main objectives of this paper are:

1) Field measurements of VES data and interpretation

2) Definition of Dar Zarrouk parameters and their relationships with aquifer transmissivity

3) Correlation between Interpreted layer resistivity and Borehole Litho-log

4) Preparation of contour maps of $T\left(\Omega \mathrm{m}^{2}\right), S\left(\Omega^{-1}\right)$, aquifer thickness $h(m)$, aquifer resistivity $\rho(\Omega \mathrm{m})$, Water Table Depth (WTD) (m), and coefficients of anisotropy

5) Delineation of prolific aquiferous zones on the basis of $T\left(\Omega \mathrm{m}^{2}\right), h(\mathrm{~m})$, and $\rho(\Omega \mathrm{m})$ values and zones of saline aquifer on the basis of $S\left(\Omega^{-1}\right)$ values in the study area.

\section{Description of Study Area}

The study area falls within Southeastern Nigeria in the Afikpo Basin, bounded by Long. $7^{\circ} 45^{\prime} \mathrm{E}$ to $8^{\circ} 00^{\prime} \mathrm{E}$ and 
Lat. $5^{\circ} 43^{\prime} \mathrm{N}$ to $5^{\circ} 57 \mathrm{~N}$ (in Nigerian local datum) and traverses two regions; the Ohaozara area and Afikpo province-consisting of Amasiri, Ozziza, and Unwana, covering an area of about $607.75 \mathrm{Km}^{2}$ (Figure 1). The area lies mostly in the (Eboine) River Basin and the Cross River plains on the South-Eastern flank of the AbakalikiBenue anticlinorium (Figure 2(a)). The area has an undulating terrain and an elevation of about $170 \mathrm{~m}$ above mean sea level. Remarkably, sandstone forms its ridges and the shale forms the valley. The shale unit underlies the bioturbated sandstone. The bioturbated sandstone has very high altitude, this is possibly because they have less period of exposure to erosion.

\section{Geology and Hydrogeology of the Study Area}

Geologically, the area falls within the Cretaceous Abakaliki-Benue Rift (Figure 2(a)), and is underlain by the Asu River Group (Albian), the Turonian Eze-Aku Formation and the (Late Campanian-Early Maastrichtian) Nkporo Formation. The Eze-Aku Group is highlighted yellow in Figure 2(b). [12] described the sediments of the Eze-Aku as consisting largely of hard flaggy calcareous shale and siltstones, usually dark grey or black in colour and contain frequent impression of inoceramus and minor sandstone beds. Occasionally, thick sandstones

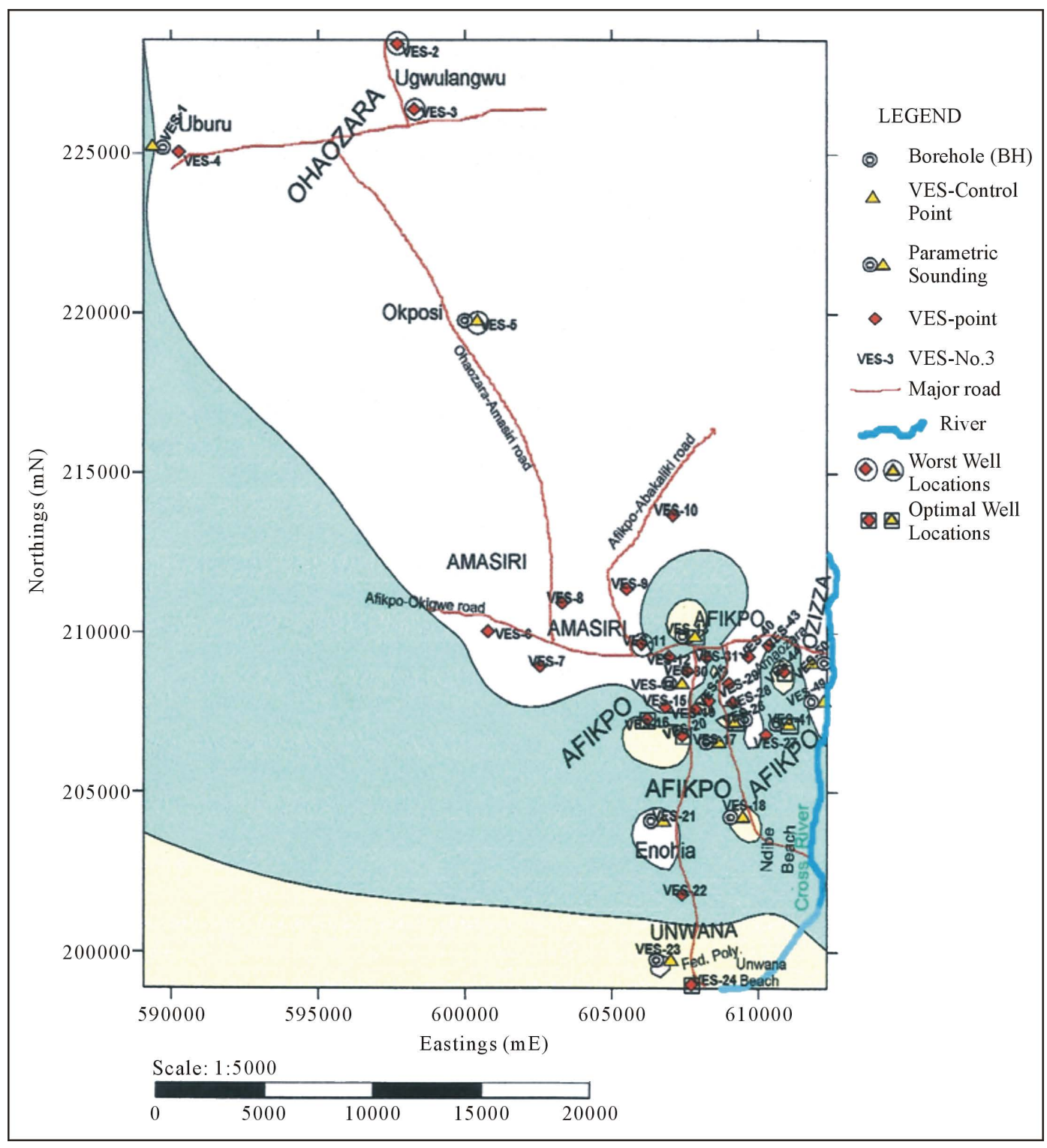

Figure 1. Showing the study area with access roads, VES stations, and Borehole points. 


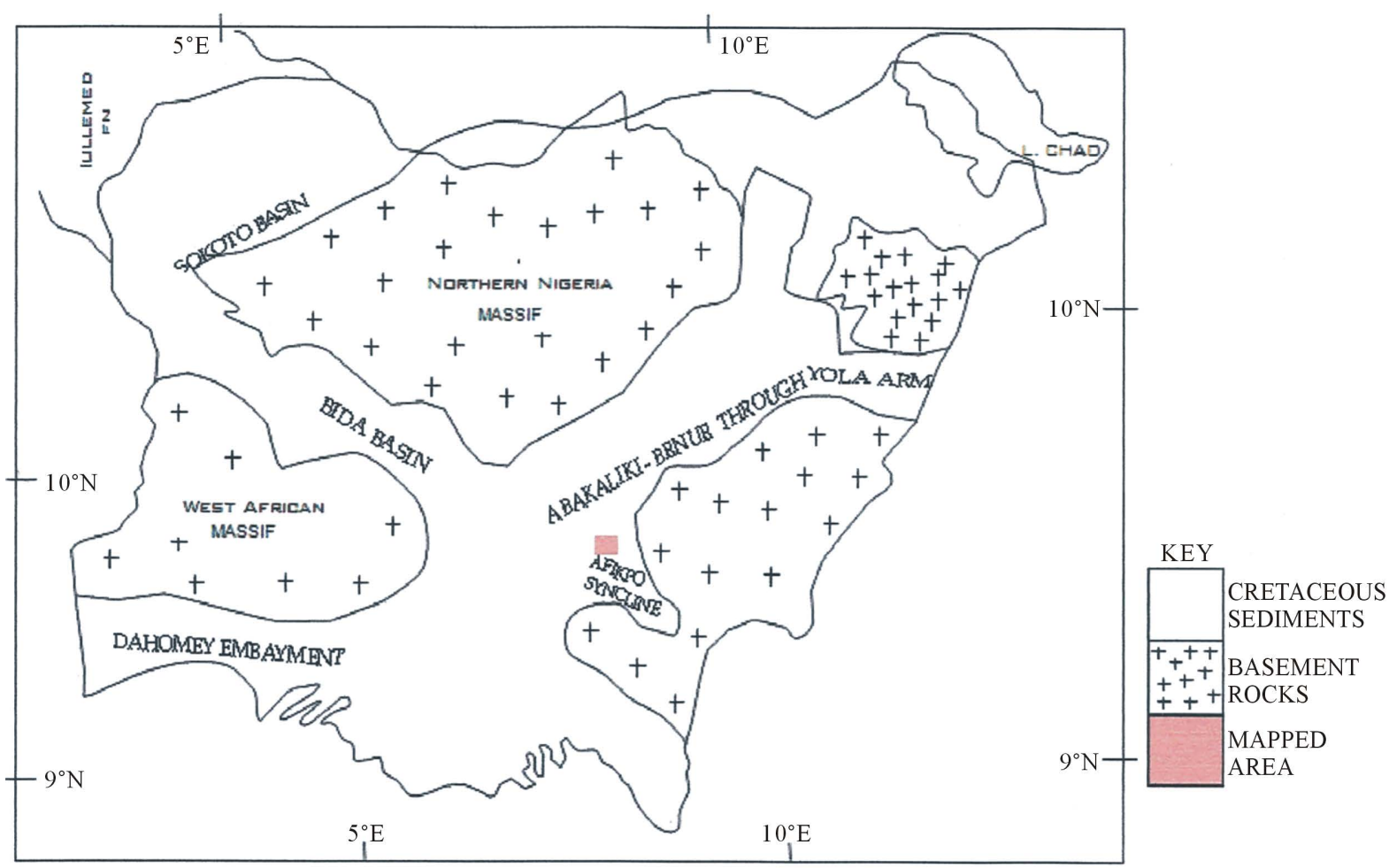

(a)

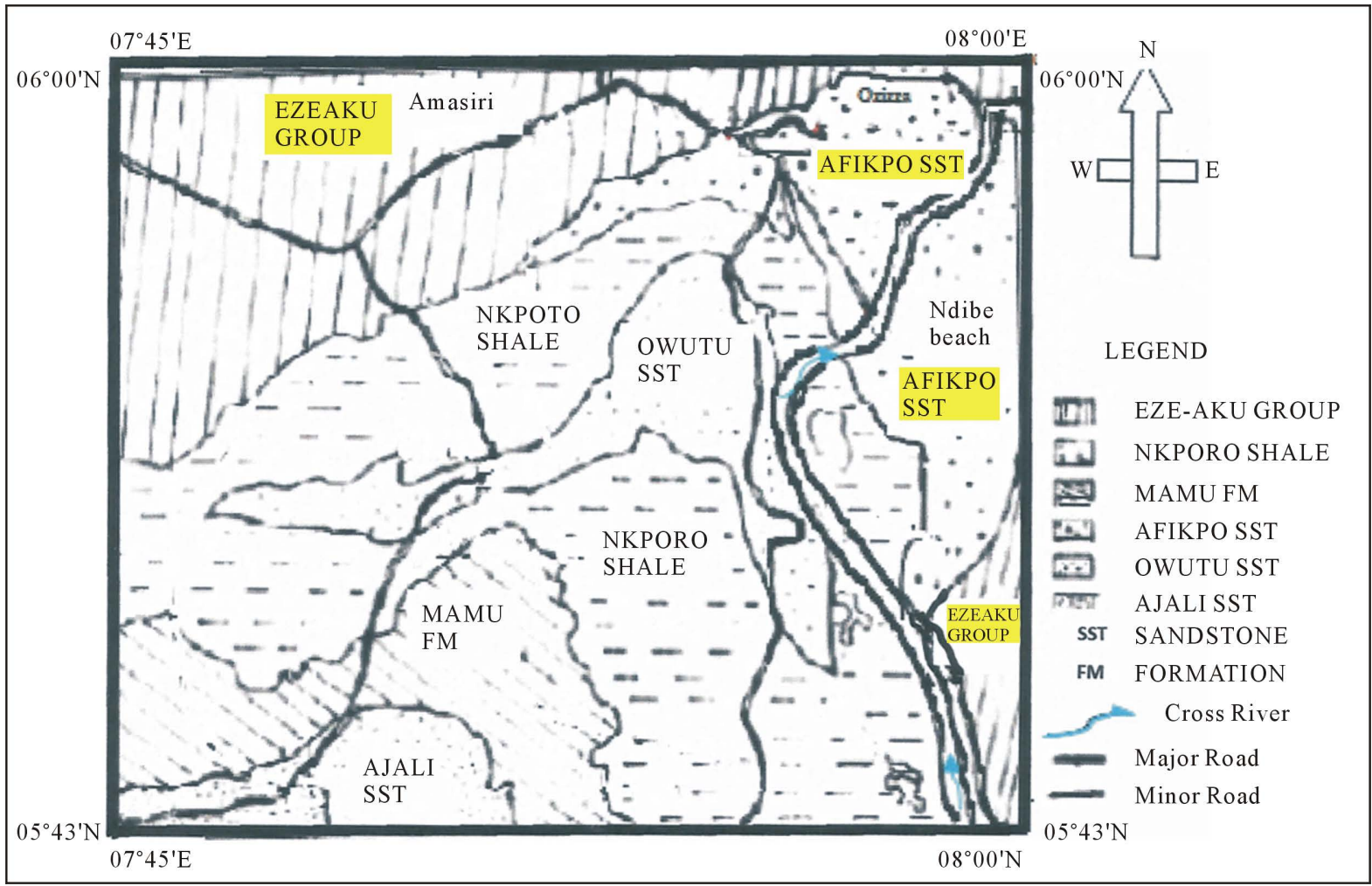

(b)

Figure 2. (a) Map of Nigeria showing the distribution of cretaceous sediments; (b) Showing Geological Map of the study area. 
or limestone units alternate with the calcareous shales. The Turonian Amasiri Sandstone of the Eze-Aku Group is a highly consolidated, well cemented, subangular to subrounded, poorly sorted, very fine to medium grained feldspathic arenite with poor reservoir quality [13]. This unit dominates the northern parts of the study area. Local geology of the study area indicates that extensive marine transgression and regression occurred in the Turonian followed by the period of Orogeny during the Coniancian, especially the Santonian. Contemporaneous with the Orogeny was the intrusion of the igneous bodies described as dolerite sills, into the Eze-Aku Shale [14] [15].

The Nkporo Formation is the basal lithostratigraphic unit of the Afikpo Sub-basin and comprises dominantly of dark grey to black shales, sandstone, minor limestone and oolitic ironstone beds. In the Campanian-Maastrichtian, there was subsidence and a marine regression resulted in the deposition of a lateral equivalent to Nkporo Formation named Afikpo Sandstone. The Afikpo Sandstone and the Nkporo shale in alternating sequence within the Afikpo Sub-basin, are Members of the Nkporo Formation. This sandstone unit underlies the hilly terrain of Afikpo town, trending eastwards across the Cross River at Ozizza and Ndibe Beach areas. The sandstones, highlighted yellow in Figure 2(b), occur as two sandstone bodies [16] [17] representing the Afikpo Sandstone. [16] [17] and [18], reported the presence of an angular unconformity between the Campanian-Maastrichtian Afikpo Sandstone and the Turonian Eze-Aku Group. The Afikpo Sandstone is the youngest sedimentary unit in the study area. Its relatively loose structure, coarse grains, sorting enables it to be porous and permeable. The formation covers most parts of Afikpo town hence the name, Afikpo Sandstone.

Shale and sandstone are the two major lithologic units in the area. The sandstone units constitute the permeable and saturated aquifers. Afikpo sandstone varies from coarse grained to fine texture, pebbly, poorly sorted, friable, except on places where weathered iron products become secondary cementing materials and increases the strength. The dominant lithology in the Southern zone of the study is the Afikpo Sandstone. Almost the entire Northern area is underlain by well compacted, hard Amasiri Sandstone of the Santonian Eze-Aku Group. The nature of this unit obviously reduces infiltration unless in parts that are fractured or deeply weathered. It is possible that the regional Cretaceous tectonic activity shattered the rocks of the area after the deposition of the sediments. Hence, places that exhibit intense fracturing yield water at shallow depth [19].

\section{Methodology-DC-Resistivity Measurement}

Geoelectrical data was obtained using the Schlumberger array with maximum current electrode spacing of $A B=$ $1362 \mathrm{~m}$. The ABEM Terrameter SAS 1000 was used, which transmits a well defined and regulated square wave that minimizes induction effects and attenuation. The VES points were located using Hand-held GPS-Garmin 76cxs. The positions of the sounding points are shown in Figure 1, with 13 Parametric Soundings [20] [21], symbolized by double circles and triangles. The method is based on measuring the potentials between a pair of electrodes, while transmitting direct current (DC) between another electrode pair. The depth of penetration is proportional to the separation between the current electrodes. By varying the electrical electrode separation, information about stratification of the ground is provided. The apparent resistivity $\left(\rho_{\text {app }}\right)$ of the medium for Schlumberger array is computed from the measurement of potential difference $\left(\Delta V_{M N}\right)$ and injected current (I) as:

$$
\rho_{\text {app }}=\frac{\pi L^{2} \Delta V_{M N}}{2 l I}=K \frac{\Delta V_{M N}}{I}
$$

where $L=A B / 2, \quad l=M N / 2, \pi L^{2} / 2 l$ denotes the geometric factor $(\mathrm{K})$ of the electrode configuration, $\Delta V_{M N}$ represents the potential difference between the potential electrodes $\mathrm{M}$ and $\mathrm{N}$, and I is the current injected into the ground. The geometric design for this array is shown in Figure 3. The VES curves (resistivity field curves) were obtained by plotting apparent resistivity, $\rho(\Omega m)$ as the ordinate, and half electrode spacing, $A B / 2(\mathrm{~m})$ —as the abscissa, in a log-log graph. The log-log graph is preferred because the sampling was logarithmically spaced. Inversion software, Interpex IX 1D, Ver. 3 (S/No. 1226), was used to reduce the VES curves into values of thickness and resistivity of individual layers. Sounding data were interpreted using Zohdy's method for the automatic interpretation of sounding curves [22], which leads to a geologically reasonable layer structured models that may be accepted or modified in order to agree with available geological information. Thus, the software generated the number, thickness, and resistivity of the various layers. A total of 50 VES stations were sampled, and the detailed interpretation of sounding curves is contained in [23]. 


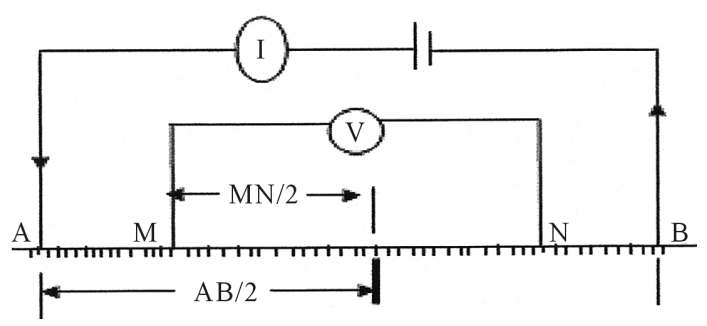

Figure 3. The Schlumberger array for vertical electrical sounding.

\section{Definition of Dar Zarrouk Parameters}

A geoelectric layer is described by two fundamental parameters: its resistivity $\rho_{i}$ and its thickness, $h_{i}$, where the subscript $i$ indicates the position of the layer in the section ( $i=1$ for the uppermost layer). Dar Zarrouk parameters; Total Transverse unit Resistance, $T\left(\Omega m^{2}\right)$ and Total Longitudinal Unit Conductance, $S\left(\Omega^{-1}\right)$ [24], including coefficient of anisotropy $\lambda$, are derived from the exact resistivity distribution of the given medium by considering a column of unit square cross-section $(1 \times 1$ metre) area cut out of a group of $n$ layers of infinite lateral extent.

For $n$ layers, the total longitudinal unit conductance is

$$
S=\sum_{i=1}^{n} \frac{h_{i}}{\rho_{i}}=\frac{h_{1}}{\rho_{1}}+\frac{h_{2}}{\rho_{2}}+\frac{h_{3}}{\rho_{3}}+\cdots+\frac{h_{n}}{\rho_{n}}\left(\Omega^{-1}\right)
$$

The total transverse unit resistance is

$$
T=\sum_{i=1}^{n} h_{i} \rho_{i}=h_{1} \rho_{1}+h_{2} \rho_{2}+h_{3} \rho_{3}+\cdots+h_{n} \rho_{n}\left(\Omega \mathrm{m}^{2}\right)
$$

and in the case of a stratified or a fractured anisotropic medium [9] [25], the coefficient of anisotropy is

$$
\lambda=\sqrt{\frac{\rho_{T}}{\rho_{L}}}
$$

where $\rho_{T}$ and $\rho_{L}$ are the average transverse resistivity and average longitudinal resistivity respectively. For homogeneous isotropic media, $\lambda=1$, whereas it ranges from 1 to 2 in homogeneous anisotropic media in which $\rho_{T}$ is greater than $\rho_{L}$ [9] [26].

But,

$$
\rho_{L}=\frac{H}{S}=\frac{\sum_{i}^{n} h_{i}}{\sum_{i}^{n} \frac{h_{i}}{\rho_{i}}}
$$

and

$$
\rho_{T}=\frac{T}{H}=\frac{\sum_{i}^{n} h_{i} \rho_{i}}{\sum_{i}^{n} h_{i}}
$$

where the quantities, $h_{i} / \rho_{i}$ and $h_{i} \rho_{i}$ are the secondary geoelectric parameters relevant to the description of geoelectric section consisting of several layers, and are referred to as longitudinal unit resistance $\left(S_{i}\right)$ and transverse unit resistance $\left(T_{i}\right)$ respectively.

Substituting Equations (5) and (6) in Equation (4),

$$
\lambda=\sqrt{\frac{T S}{H H}}=\frac{\sqrt{T S}}{H}
$$


The quantity $S_{i}=h_{i} / \rho_{i}$ can be written as $S_{i}=\sigma_{i} h_{i}$, where $\sigma_{i}$ is the conductivity (inverse of resistivity), and is analogous to transmissivity, $T_{i}=K_{i} b_{i}$ used in groundwater hydrology, where $K_{i}$ is the hydraulic conductivity of the $i^{\text {th }}$ layer and $b_{i}$ is its thickness. The mathematical analogy between electrical flow and groundwater flow has long been recognized and widely accepted [27] [28]. The analogy of Darcy's law and Ohm's law are the basis for many electrical analog methods for groundwater systems [29]. In general terms, since larger connected pores make for better flow characteristics for both water and electric currents it is expected that at the very least there should be some relationship between electrical and hydraulic parameters.

On the basis of the analogy between Darcy's law of groundwater flow and Ohm's law of electric current flow in a horizontal, homogeneous, and isotropic medium, [7] showed that aquifer Transmissivity, $T_{r}$ is:

$$
T_{r}=K \sigma T
$$

or

$$
T_{r}=\frac{K S}{\sigma}
$$

They assumed that the quantities $(K \sigma)$ or $(K / \sigma)$ remained fairly constant within the investigated area. In further analysis of these two equations, [30] effectively explained the contradiction between direct and inverse relationship of electrical resistivity and hydraulic conductivity. They concluded that Equation (8b) exists in case of highly resistive basement (S-dominant aquifer where electrical current flows parallel to the bedding plane) and Equation (8a) exists in case of highly conducting basement (T-dominant aquifer when the electrical current tends to flow perpendicular to the bedding plane). The geology of the study area corresponds to Equation (8a); the target aquifer (Afikpo Sandstone) is underlain by shale material.

\section{Results and Discussions}

The results and discussions are presented in segments as shown in the subsections under this heading.

\subsection{Interpretation of Sounding Curves}

The results of the quantitative interpretation suggest that the sites are characterized by 21 resistivity type-curves. This is because the shape of a VES curve depends on the number of layers in the substratum, the thickness of each layer, and the ratio of the resistivity of the layers [31], and also reflects different lithological attributes in the area. The type curves include; 6-KHKH, 4-QHKH, 1-KHAK, 2-QHK, 1-QHAA, 1-QHAK, 4-KQHA, 1-AKQQ, 5-KHK, 2-KHKQ, 1-AKHK, 2-KQQ, 2-KQHK, 3-AKHA, 5-HKHA, 2-HKHK, 3-KHAK, 1-HKH, 2-KHA, 1-KHAA, and 1-HKQH). For example, Figure 4(a) shows a type curve-QHK of layer resistivity section $\left(\rho_{1}>\rho_{2}>\rho_{3}<\rho_{4}>\rho_{5}\right)$ for VES-5 with the associated layer model (Figure 4(b)) in the study area. Further quantitative treatment and analysis of the data delineate four to five distinct geoelectric layers in the study area (surface layer, shallow layer, saturated zone, which extends to the fourth geoelectric layer at some sites, and a fifth layer which appears to be relatively more conductive at some VES sites and more resistive at few other sites). The surface unit (lateritic) which has large variation in resistivity ranging from $96.98 \Omega \mathrm{m}-33,525.10 \Omega \mathrm{m}$ and average value of $1820.41 \Omega \mathrm{m}$ is found in all the VES locations with varying thickness of $0.247 \mathrm{~m}-7.17 \mathrm{~m}$ and average thickness value of $1.10 \mathrm{~m}$. Underlying the surface unit is the shallow unit with resistivity range of $34.85 \Omega \mathrm{m}-114,794.3 \Omega \mathrm{m}$ and average value of $8974.24 \Omega \mathrm{m}$. This unit has thickness range of $0.304 \mathrm{~m}-38.76$ $\mathrm{m}$ and average thickness value of $5.99 \mathrm{~m}$. This shallow unit consists of fine grained to coarse grained dry sand. The saturated aquifers in the study area are found in third and fourth geoelectric layers. In the third geoelectric layer these units have resistivity range of $8.39 \Omega \mathrm{m}-7169.3 \Omega \mathrm{m}$ and average resistivity value of $1782.57 \Omega \mathrm{m}$ with thickness range of $2.4 \mathrm{~m}-277 \mathrm{~m}$ and mean thickness of $41.64 \mathrm{~m}$. In the fourth layer, the saturated zones have resistivity range of $32.98 \Omega \mathrm{m}-26,004.8 \Omega \mathrm{m}$ and average resistivity value of $3077.12 \Omega \mathrm{m}$ with thickness range of $2.4 \mathrm{~m}-277 \mathrm{~m}$ and mean thickness of $68.77 \mathrm{~m}$. These units are indicated in the geoelectrical model of subsurface layers (Figure 5) to be made up of earth materials ranging from saturated fine sand, medium, to very coarse sand. The variation in conductivity of this saturated zone may be due to the varying amount of dissolved impurities. The conductivity of a porous rock varies with the volume and arrangement of the pores and even more with the conductivity and amount of contained water [32]. Water conductivity varies considerably depending on the amount and conductivity of dissolved chlorides, sulphates and other minerals present [33]. For 


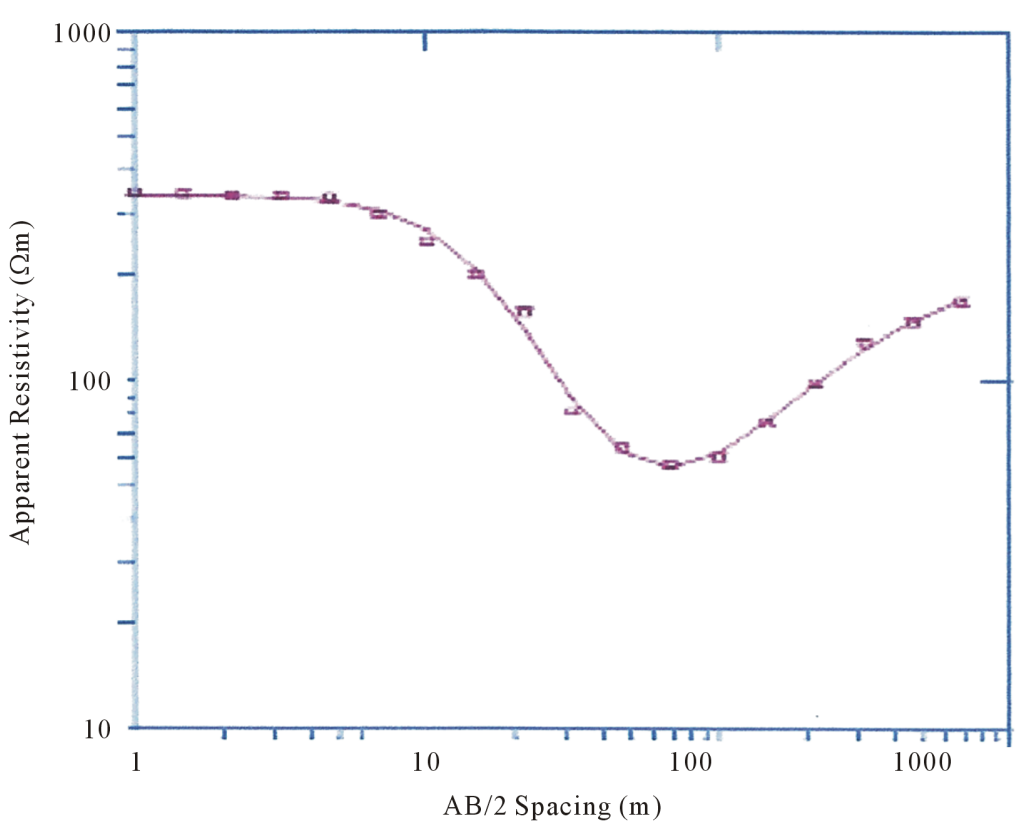

Resistivity Curve VES-5

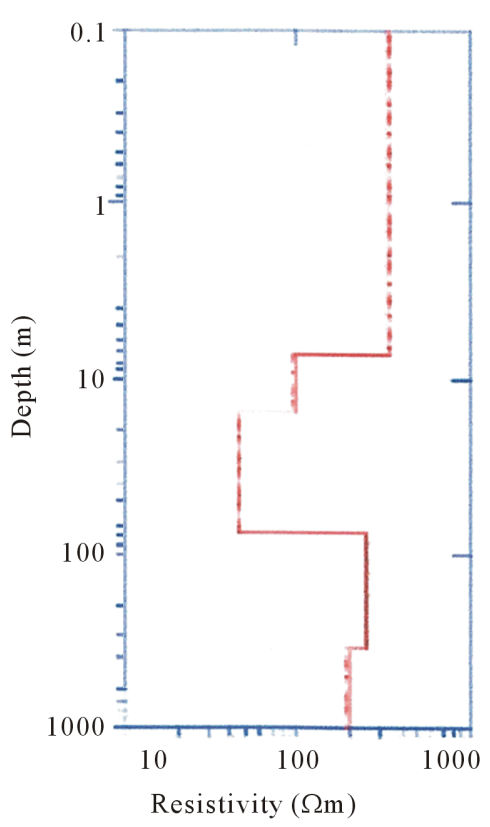

Layer Model VES-5

(a)

(b)

Figure 4. (a) Resistivity curve VES-5 (type curve-QHK); (b) Layer model VES-5.

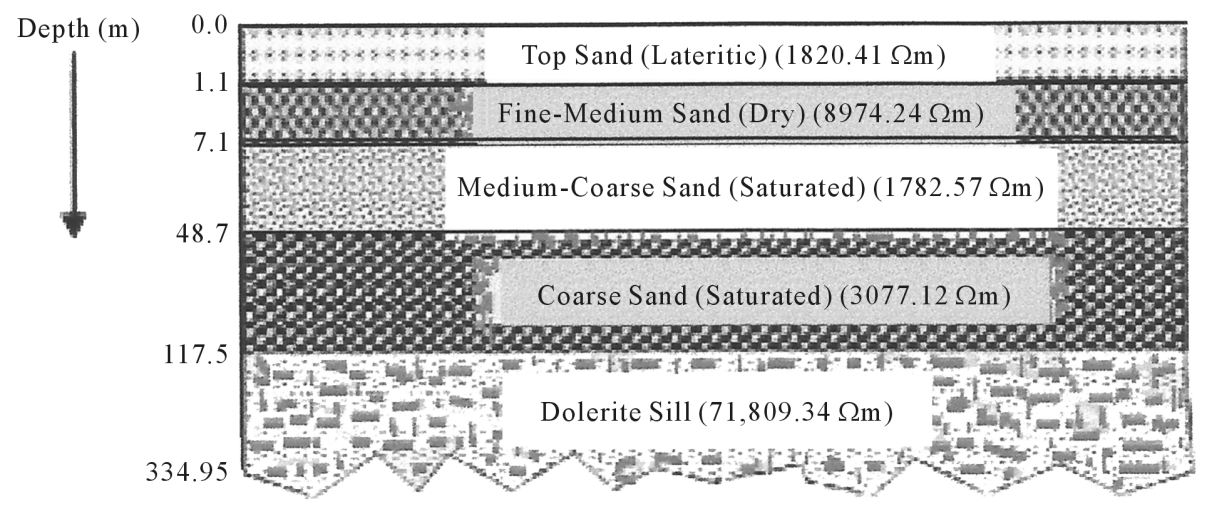

(a)

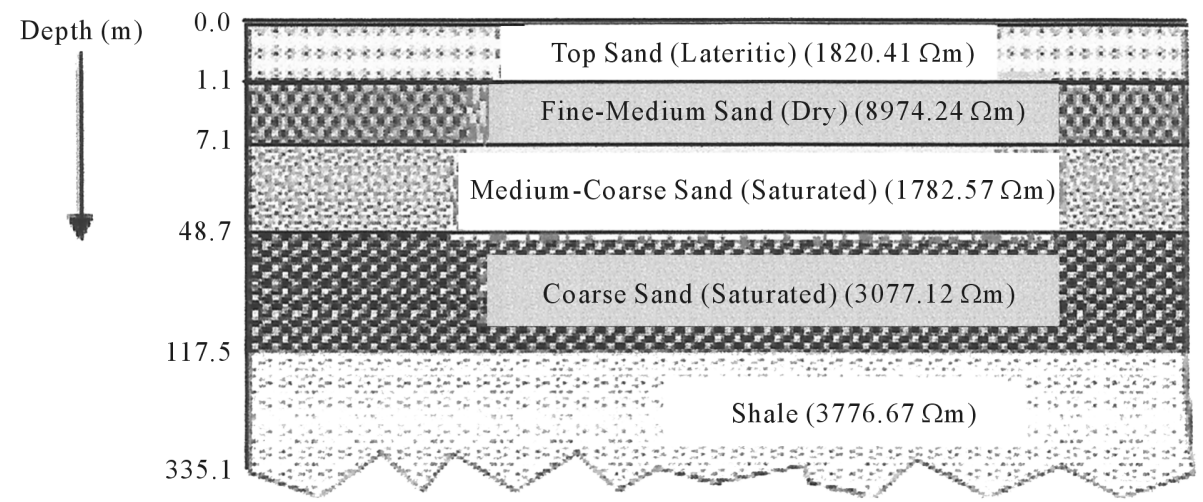

(b)

Figure 5. (a) A geoelectrical model of subsurface layers in the area indicating the presence of dolerite sill; (b) A geoelectrical model of subsurface layers in the study area. 
high water resistivities and small grain sizes, the electrical current is not only conducted by the pore fluid but also by the grain matrix [34]. A fifth geoelectric layer which was not well developed in some VES locations has resistivity of 25,534.5 $\Omega \mathrm{m}-201,083.2 \Omega \mathrm{m}$ at seven VES sites namely; VES-6, VES-10, 16, 25, 39, 41, and 45. In these VES-sites, the average resistivity is $71,809.34 \Omega \mathrm{m}$ with thickness range of $34.12 \mathrm{~m}-356.00 \mathrm{~m}$ and average thickness of $217.44 \mathrm{~m}$. These materials (Figure 5(a)), according to distribution diagrams of resistivities of common rocks and sediments as compiled by [33] [35] [36], may likely be a dolerite sill of Santonian activity encountered in the study area which intruded between Junction shale-1 and Junction shale-2 and generally trends in the East-West direction [14] [15]. The fifth geoelectric layer at other thirty two VES sites, appear to be more conductive with resistivity values ranging between $15.45 \Omega \mathrm{m}-17,364.9 \Omega \mathrm{m}$ and average resistivity value of $3776.67 \Omega \mathrm{m}$ with thickness range of $104.00 \mathrm{~m}-319.7$ and mean thickness of $217.59 \mathrm{~m}$. This unit, shown in Figure 5(b), may likely be shale of varying age [37].

\subsection{Correlation between Interpreted Layer Resistivity and Borehole Litho-log}

Resistivity data are usually associated with errors produced by principles of suppression and equivalence. They are also sensitive to porosity and water content of the aquifer as well as the mineralization and salinity of groundwater. Therefore, for effective use of the geoelectric data, it was important to compare the VES results with borehole data based on the borehole lithology and geoelectrical column correlations [21]. To correlate the VES interpretation results with the borehole data, two types of models; borehole model constructed manually using borehole data collected from the field, and geoelectrical model of subsurface layers produced using the interpreted resistivity values and layer thickness data (Figure 5), were prepared for each of 13 parametric soundings. Experimental studies have shown that a correlation exists between rock resistivity and the particle size of sedimentary materials [33] [35] [36]. This general relationship has been adopted as a guide in the correlation attempt. A correlation treatment carried out between resistivity record and litholog borehole data demonstrated that borehole log information matched approximately well with the VES data in the study area. A geoelectrical model of subsurface layers for a parametric sounding, VES-5 station (Figure 6(a)) and the corresponding borehole litho-log data for borehole-BH2 (Figure 6(b), Table 1) has been shown as an example. Also, Water Struck Depths at the 13 parametric sounding stations well imaged the depths to water table-level information obtained from borehole litho-log as shown in Table 1. For example, in Figure 6, correlation of borehole litho-log (Figure 6(b)) and the subsurface geoelectrical model (Figure 6(a)) indicates that the water table level at $17.9 \mathrm{~m}$ corresponds to the water struck depth at $15.8 \mathrm{~m}$ in the geoelectrical model of the subsurface layers (Table 2).

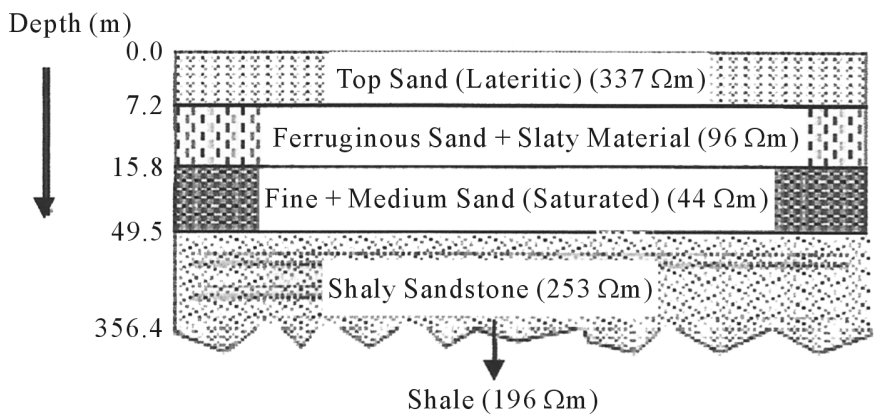

(a)

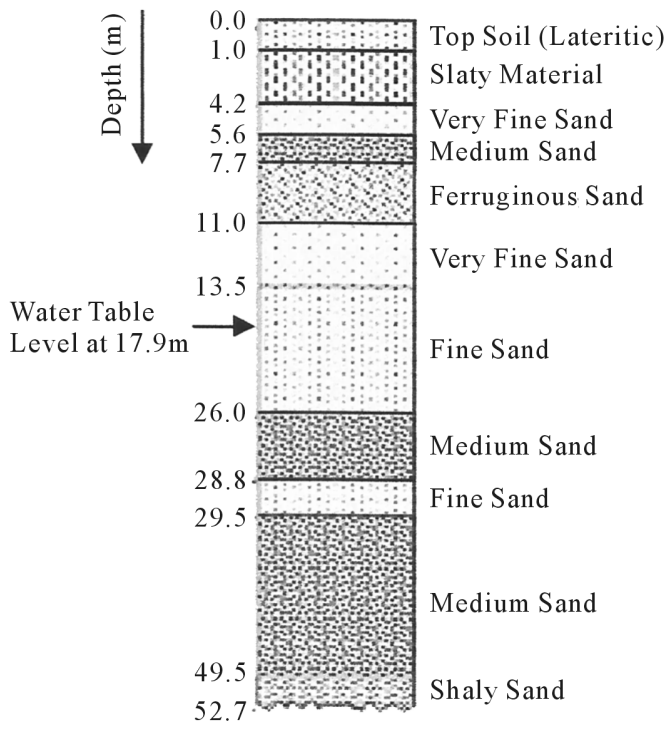

(b)

Figure 6. (a) A geoelectrical model of subsurface layers for sounding VES-5 station; (b) Borehole litho-log for parametric borehole-BH2. 
Table 1. Results of Calibration at (13) parametric sounding stations.

\begin{tabular}{cccccc}
\hline $\begin{array}{c}\text { (Parametric) } \\
\text { Sounding } \\
\text { Stations }\end{array}$ & \multicolumn{2}{c}{ Station Coordinates } & Saturated Zone (VES) & & Borehole litho-log \\
\cline { 2 - 6 } & Easting $(\mathrm{mE})$ & Northing $(\mathrm{mN})$ & $\begin{array}{c}\text { Water struck } \\
\text { depth }(\mathrm{m})\end{array}$ & Borehole (BH) & $\begin{array}{c}\text { Depth to water table } \\
\text { level (m) }\end{array}$ \\
\hline Uburu VES-1 & $589,069.364$ & $225,241.733$ & 2.43 & BH 1 & 11.60 \\
Okposi VES-5 & $600,242.627$ & $219,835.010$ & 15.79 & BH 2 & 17.90 \\
Idugaway VES-14 & $607,167.925$ & $208,535.525$ & 1.60 & BH 3 & 14.20 \\
Unwana VES-21 & $606,594.353$ & $204,049.471$ & 2.90 & BH 4 & 12.80 \\
Fed. Poly VES-23 & $606,765.319$ & $199,789.908$ & 18.52 & BH 5 & 19.70 \\
St. Pat. VES-17 & $608,534.698$ & $206,725.360$ & 4.12 & BH 6 & 15.20 \\
Beach Rd. VES-18 & $609,298.081$ & $204,264.789$ & 13.40 & BH 7 & 16.60 \\
Nkpogoro VES-26 & $608,993.471$ & $207,246.962$ & 14.90 & BH 8 & 17.70 \\
Amaozara VES-41 & $610,891.026$ & $207,214.397$ & 11.79 & BH 9 & 16.50 \\
Orah VES-49 & $612,060.318$ & $207,852.033$ & 4.48 & BH 10 & 10.90 \\
Ozizza VES-50 & $611,643.342$ & $209,203.632$ & 1.55 & BH 11 & 8.60 \\
Low Cost VES-38 & $609,250.253$ & $208,776.030$ & 9.41 & BH 12 & 15.8 \\
Govt. Col. VES 13 & $607,615.361$ & $209,993.765$ & 8.22 & BH 13 & 12.1 \\
\hline
\end{tabular}

\subsection{Transverse Resistance, Aquifer Thickness, and Aquifer Resistivity}

Hydrogeophysical maps produced from the resistivity data include: aquifer transverse resistance $(T)$, aquifer thickness $(h)$, aquifer resistivity $(\rho)$, aquifer longitudinal conductance $(S)$, aquifer depth or water table depth (WTD) $(m)$, and coefficients of anisotropy, $\lambda$. The computed data for each of these parameters are presented in Table 2. Figure 7(a), the transverse resistance map, shows that the aquifer in the Southern part of the study area majorly reflects higher transverse resistance values relative to the Northern part. This indicates that the southern part has high transmissivity with good groundwater potential. The transverse resistance varies between 2341 $\Omega \mathrm{m}^{2}$ at Okposi, in the Northern part of the study area to 4,321,879 $\Omega \mathrm{m}^{2}$ at Ngodo, in the southern part of the area. An isopach map of the aquiferous layer (Figure 8(a)) shows that aquifer thickness is highly variable in the study area, ranging from $27.43 \mathrm{~m}$ at VES-8, North of the study area, to $165.90 \mathrm{~m}$ at VES-44 (Amaozara) in the Southern part of the study area, with average value of $66.74 \mathrm{~m}$. Comparison of Figure 7(a) with Figure 8(a) shows that areas underlain by relatively thick aquifer materials have higher T-values than areas underlain by relatively thin aquifer materials. This relationship is expected, because aquifer transmissivity has a linear relationship with aquifer thickness and Transverse resistance since hydraulic conductivity is assumed constant.

The aquifer resistivity across the study area has been presented as a contour map in Figure 9(a). The distribution of resistivity values indicates that two distinct zones can be identified in the study area; the Southern part (Afikpo, Ozizza, and Unwana) reveals the existence, of relatively very high resistive aquifers with resistivities ranging from $32.27 \Omega \mathrm{m}$ at VES-32 (Okogeri road, Ukpa) to $26004.8 \Omega \mathrm{m}$ at VES-45 (Amaozara) with average aquifer resistivity of $2690.081 \Omega \mathrm{m}$, above the regional average of $2263.609 \Omega \mathrm{m}$ and the Northern part (Amasiri and Ohaozara) which confirms the presence of low resistive/high conductive aquifers with resistivities ranging from $14.87 \Omega \mathrm{m}$ at VES-11, near De-Base hotel to 6005.2 at VES-1, Uburu, with average aquifer resistivity of $751.575 \Omega \mathrm{m}$, below the regional average resistivity.

Despite the fact that the contour maps shown in Figure 7(a), Figure 8(a), and Figure 9(a) for the $T, h$, and $\rho$ values respectively, point to intercalations of low values of the parameters at the S-SE zone of the area, generally, they reveal a relatively progressive decrease in values of the aquifer parameters in the South-North direction, thereby indicating similar trend patterns in the distribution of these parameter values in the study area. This condition is confirmed by the longitudinal profiles; A-B (Figure 7(b), Figure 8(b), and Figure 9(b)) corresponding to each of the Figure 7(a), Figure 8(a), and Figure 9(a) respectively. The profiles show similarity in trend patterns of the productivity of the aquiferous zones on the basis of the $T, h$, and $\rho$ values, representing a progressive 
Table 2. Results of vertical electrical sounding in the study area.

\begin{tabular}{|c|c|c|c|c|c|c|c|c|}
\hline VES No. & Easting (mE) & Northing (mN) & $T\left(\Omega m^{2}\right)$ & $\begin{array}{l}S\left(\Omega^{-1}\right) \\
\left(\Gamma^{n} h_{i}\right)\end{array}$ & $h(m)$ & WTD $(m)$ & $\rho(\Omega m)$ & $\lambda$ \\
\hline 1 & $589,069.364$ & $225,241.733$ & $716,630.734$ & 0.80839119 & 89.78 & 2.43 & 6005.200 & 2.469 \\
\hline 2 & $597,541.102$ & $228,572.138$ & $288,207.414$ & 4.869766639 & 40.3 & 7.42 & 389.800 & 3.814 \\
\hline 3 & $598,036.634$ & $226,470.968$ & $335,185.57$ & 0.666456959 & 39.99 & 32.56 & 308.000 & 1.352 \\
\hline 4 & $590,068.517$ & $225,145.188$ & $727,947.8$ & 4.6429537 & 23.83 & 12.35 & 59.600 & 4.97 \\
\hline 5 & $600,242.627$ & 219,835.01 & $76,671.8864$ & 2.590525356 & 61.11 & 15.79 & 44.450 & 1.251 \\
\hline 6 & $600,625.099$ & $210,096.49$ & 7,696,646.138 & 0.780366258 & 61.67 & 8.06 & 89.485 & 6.609 \\
\hline 7 & $602,315.315$ & $208,958.34$ & $1,825,500.026$ & 3.693652763 & 47.7 & 8.62 & 20.685 & 7.337 \\
\hline 8 & $603,111.515$ & $210,993.516$ & $84,295.473$ & 3.342862221 & 27.43 & 4.52 & 1031.375 & 1.368 \\
\hline 9 & $605,233.508$ & $211,476.439$ & $5,418,148.926$ & 1.928330847 & 36.09 & 40.12 & 21.760 & 9.674 \\
\hline 10 & $606,828.818$ & 213,691.99 & $14,170,741.01$ & 0.1783587 & 38.63 & 11.81 & 282.100 & 4.295 \\
\hline 11 & $605,754.414$ & $209,670.17$ & $158,593.3619$ & 19.37927367 & 50.17 & 3.73 & 14.870 & 4.727 \\
\hline 12 & $606,688.941$ & $209,294.541$ & $296,124.1116$ & 0.873400829 & 71.00 & 21.21 & 1243.600 & 1.556 \\
\hline 13 & $607,615.361$ & 209,993.765 & $4,415,438.826$ & 0.141241509 & 154.1 & 8.22 & 1227.400 & 1.962 \\
\hline 14 & $607,167.925$ & $208,535.525$ & 3,486,327.925 & 0.266372599 & 29.38 & 1.6 & 817.500 & 2.913 \\
\hline 15 & $606,588.987$ & $207,749.96$ & $4,404,234.615$ & 0.029207206 & 37.37 & 2.55 & 5997.500 & 1.098 \\
\hline 16 & $605,958.003$ & 207,331.47 & $40,299,947.02$ & 0.078775891 & 112.72 & 10.14 & 2456.700 & 5.543 \\
\hline 17 & $608,534.698$ & $206,725.36$ & $1,038,237.362$ & 0.206833941 & 54.55 & 4.12 & 955.200 & 1.297 \\
\hline 18 & $609,298.081$ & $204,264.789$ & $512,351.861$ & 0.93262515 & 113.9 & 13.4 & 1008.800 & 2.819 \\
\hline 19 & $607,606.803$ & $207,629.151$ & $2,017,954.964$ & 0.126439103 & 45.08 & 9.15 & 556.00 & 1.568 \\
\hline 20 & $607,160.08$ & $206,871.084$ & $1,054,332.912$ & 0.61871871 & 139.58 & 17.82 & 2401.650 & 1.855 \\
\hline 21 & $606,594.353$ & $204,049.471$ & $187,216.291$ & 2.824479845 & 49.59 & 2.9 & 1603.250 & 2.28 \\
\hline 22 & $607,167.245$ & $201,825.528$ & $525,200.024$ & 0.715745186 & 68.28 & 2.65 & 2745.100 & 1.84 \\
\hline 23 & $606,765.319$ & $199,789.908$ & $567,217.9548$ & 0.292914786 & 151.68 & 18.52 & 861.700 & 1.24 \\
\hline 24 & $607,499.532$ & $198,870.958$ & $1,298,486.573$ & 0.157634667 & 130.6 & 34.3 & 1048.300 & 1.44 \\
\hline 25 & $608,059.173$ & 207,898.935 & 7,320,901.913 & 0.443508991 & 157 & 7.61 & 384.500 & 5.549 \\
\hline 26 & $608,993.471$ & $207,246.962$ & $1,421,375.604$ & 0.098658247 & 147.45 & 46.35 & 4108.050 & 1.158 \\
\hline 27 & $609,629.732$ & $206,871.68$ & 2,927,134.315 & 0.12420019 & 52.48 & 35.59 & 603.500 & 1.923 \\
\hline 28 & $608,821.836$ & $207,842.893$ & $1,730,113.758$ & 0.167510613 & 33.11 & 6.2 & 377.300 & 1.959 \\
\hline 29 & $608,733.068$ & $208,264.006$ & $516,369.6834$ & 0.344175149 & 58.71 & 5.59 & 323.400 & 1.399 \\
\hline 30 & $607,392.706$ & 208,793.254 & 489,373.683 & 0.062628335 & 43.9 & 3.86 & 1581.300 & 1.101 \\
\hline
\end{tabular}




\begin{tabular}{|c|c|c|c|c|c|c|c|c|}
\hline \multicolumn{9}{|c|}{ Continued } \\
\hline 31 & $607,971.364$ & $209,262.519$ & 1,046,708.397 & 0.321388013 & 30.66 & 31.47 & 20773.900 & 1.877 \\
\hline 32 & $608,057.208$ & 208,998.332 & $790,812.399$ & 1.29005801 & 40.02 & 3.42 & 32.2700 & 4.317 \\
\hline 33 & $607,832.145$ & $208,448.862$ & 1,188,682.158 & 0.346269148 & 45.94 & 11.9 & 182.900 & 2.503 \\
\hline 34 & $608,671.909$ & $208,613.847$ & $359,378.628$ & 0.395298897 & 59.52 & 9.23 & 193.200 & 1.67 \\
\hline 35 & $608,531.455$ & $209,627.396$ & $1,526,761.89$ & 0.085191537 & 64.98 & 32.66 & 895.500 & 1.275 \\
\hline 36 & $608,112.219$ & $208,654.331$ & $1,014,511.279$ & 0.434912996 & 47.81 & 16.49 & 134.900 & 2.34 \\
\hline 37 & $608,536.7$ & $208,798.238$ & $800,508.424$ & 0.143781284 & 162.1 & 31.59 & 336.800 & 1.296 \\
\hline 38 & $609,099.843$ & $209,064.847$ & $340,329.925$ & 0.265653062 & 37.79 & 9.41 & 397.600 & 1.239 \\
\hline 39 & $609,250.253$ & $208,776.03$ & $20,250,258.21$ & 0.100874639 & 32.2 & 9.12 & 336.300 & 4.709 \\
\hline 40 & $609,628.906$ & $209,156.451$ & $535,027.3692$ & 0.991347205 & 41.27 & 1.77 & 219.200 & 2.294 \\
\hline 41 & $610,891.026$ & $207,214.397$ & $6,627,827.837$ & 0.253150692 & 100.47 & 11.79 & 1337.050 & 4.235 \\
\hline 42 & $609,738.962$ & $208,487.157$ & $872,741.187$ & 0.400369723 & 28.34 & 8.92 & 224.300 & 1.687 \\
\hline 43 & $610,339.756$ & 209,597.968 & $822,925.969$ & 0.105673379 & 57.9 & 7.46 & 3852.000 & 1.033 \\
\hline 44 & $610,889.469$ & $208,789.781$ & $2,855,769.851$ & 0.055467559 & 165.9 & 91.48 & $15,404.700$ & 1.546 \\
\hline 45 & $609,857.616$ & $207,172.407$ & $40,441,846.62$ & 0.006612139 & 52.29 & 25.79 & $26,004.800$ & 1.639 \\
\hline 46 & $611,578.48$ & 208,911.957 & 2,748,917.507 & 0.1562329 & 35.29 & 4.03 & 304.000 & 1.822 \\
\hline 47 & $612,322.756$ & $208,938.89$ & $5,162,719.744$ & 0.060825935 & 44.64 & 5.2 & 1065.000 & 1.68 \\
\hline 48 & $612,315.856$ & $208,143.529$ & $519,512.4696$ & 0.547515487 & 32.7 & 1.39 & 83.770 & 1.713 \\
\hline 49 & $612,060.318$ & $207,852.033$ & $1,252,710.794$ & 0.670165408 & 38.68 & 4.48 & 157.700 & 2.609 \\
\hline 50 & $611,643.342$ & $209,203.632$ & 4,587,798.61 & 0.054902225 & 51.74 & 1.55 & 7169.300 & 1.391 \\
\hline
\end{tabular}

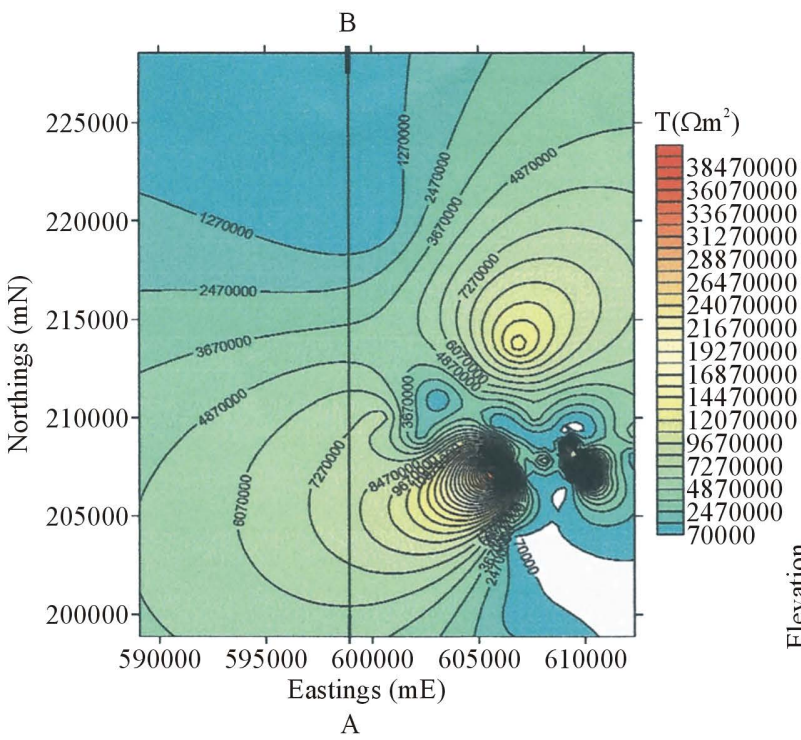

(a)

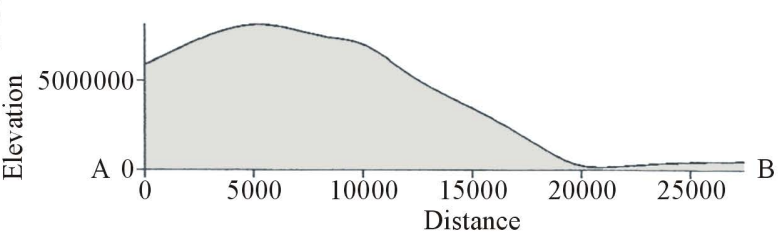

(b)

Figure 7. (a) Aquifer transverse resistance- $T\left(\Omega \mathrm{m}^{2}\right)$ contour; (b) Aquifer transverse resistance profile. 


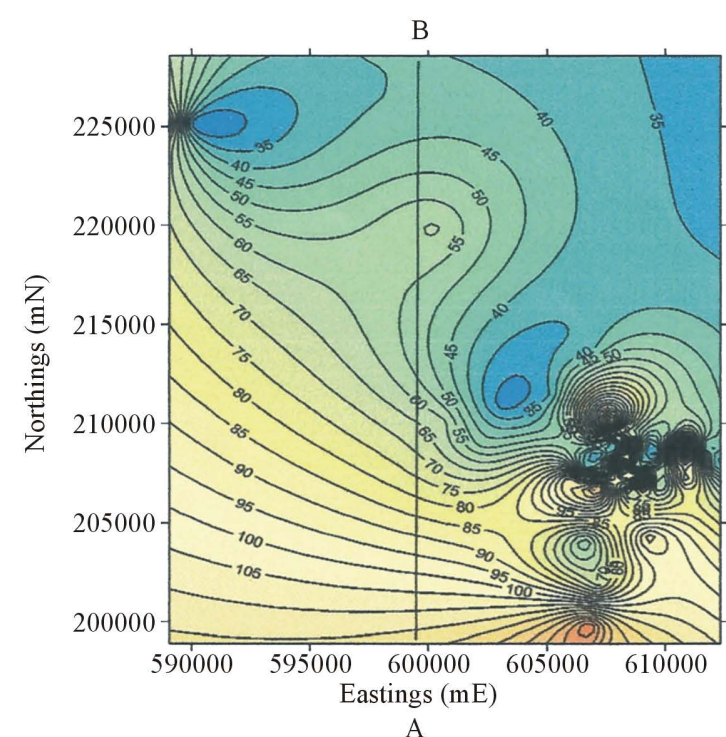

(a)

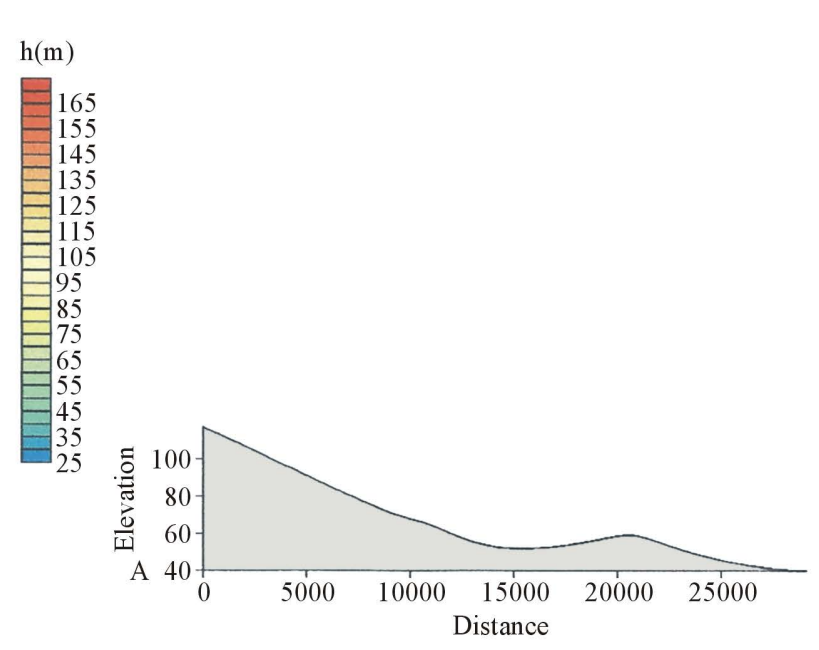

(b)

Figure 8. (a) Aquifer thickness-h (m) contour map; (b) Aquifer thickness profile.

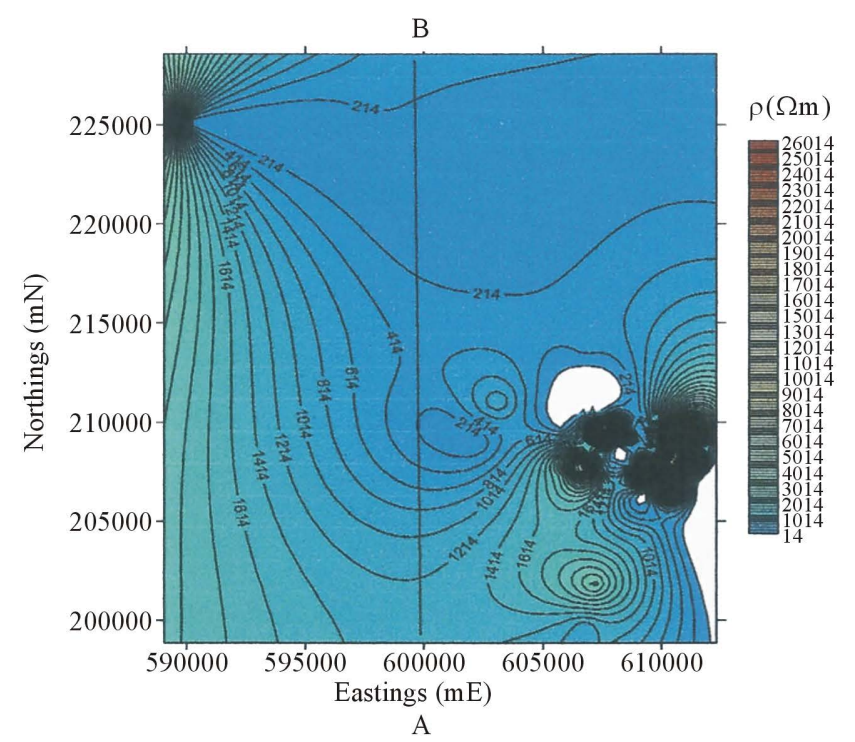

(a)

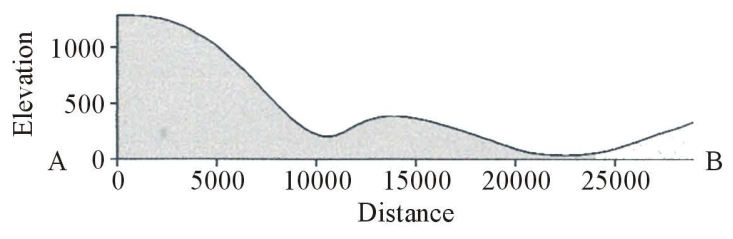

(b)

Figure 9. (a) Aquifer resistivity- $\rho(\Omega \mathrm{m})$ contour map; (b) Aquifer resistivity profile.

decrease in the aquifer yield potential, trending S-N of the study area for each of the profiles. This variation between the two areas may perhaps be attributed to variations in geology, water quality and/or degree of saturation. A geological formation reflecting a pre-dominantly high transverse resistance value indicates that its resistivity is high or it has higher thickness with favorable aquifer conditions [5]. Therefore, in the assessment of aquifer yield potentials of the aquiferous zones; on the basis of relatively higher transverse resistance, higher aquifer thickness, and higher aquifer resistivity values, it could be said that the southern part of the study area, underlain majorly by Nkporo Formation is comparatively the higher prolific aquiferous zone with the Afikpo Sandstone as the target aquifer; its relatively loose structure, coarse grains, sorting enables it to be porous and permeable. The paucity of water in the Northern region of the study area can be explained to be as a result of the dominant lithology — as almost the entire area is underlain by a well compacted, hard Turonian Amasiri Sandstone of the Eze-Aku Group. Therefore on the basis of higher, $T, h$, and $\rho$ values, soundings of VES-2, VES-3, VES-5 and 
VES-11 (Figure 1) in the study area could be said to have the worst aquifer yield potential. Also, the best locations for well drilling in this area are suggested in location of soundings VES-16, 20, 24, 26, 41, and 44 (Figure 1) because of high thickness value, high resistivity, and high transverse resistance.

\subsection{Longitudinal Conductance, Aquifer Depth, and Coefficient of Anisotropy}

The contour map of the longitudinal conductance shown in Figure 10(a) indicates that the S values, varies between $4.7 \Omega^{-1}$ at Uburu located at the Northern part of the study area and $0.006 \Omega^{-1}$ at Amaozara situated at the southern part. Also, the longitudinal profile (A-B) (Figure 10(b)), running South-North in the study area, shows a consistent increase in the value of S from south to north. The high $\mathrm{S}$ values obtained in the Uburu, Okposi, and Amasiri sections of the area may likely be as a result of high salinity of the groundwater or high clay content or both [4]. Also, the result of water analysis by [38], has shown that saltwater intrusion is prominent in Uburu and and Okposi. Thus, it could be concluded that as a result of the relatively higher S values, the northern branch of the study area has higher saline aquifer while some parts of Amasiri region in the Southern part of the study area has higher saline aquifer or clay aquifer.

The distribution of water table depths in the study area varies between 1.39 - $91.48 \mathrm{~m}$ with a regional average depth of $14.36 \mathrm{~m}$. This is shown in the contour map of water table depth (WTD) (Figure 11(a)). Even though the depth to water table tends to be low in some regions, and high in some other parts of the area, generally, the variation in the distribution of the WTD in the study area is irregular as shown in Figure 11(a), and Figure 11(b) corresponding to the profile sections- BC, and CD respectively. In harmony with the opinion of [39], the uneven spread of the WTD may perhaps, be attributed to the undulating topography of the area. Figure 12 shows the contour map of the coefficients of resistivity anisotropy in the study area. The map signifies that the ground resistivity is dependent on both the coordinates and orientation of the electrode array which suggests that the ground is anisotropic and inhomogeneous [40]. It is important to study the effects of anisotropy because anisotropic ground will lead to errors in estimating layer resistivities and layer thicknesses. If anisotropy exists in the ground, but is ignored, then the true ground resistivities and the geologic structure that are interpreted from measured apparent resistivity may be incorrect.

\section{Conclusion}

The good agreement between the iso-thickness, iso-resistivity and the transverse resistance maps, including the role of the longitudinal conductance values in discerning zones of high saline or high clay aquifers, emphasizes the contribution of Dar Zarrouk parameters to the delineation of aquiferous zones.

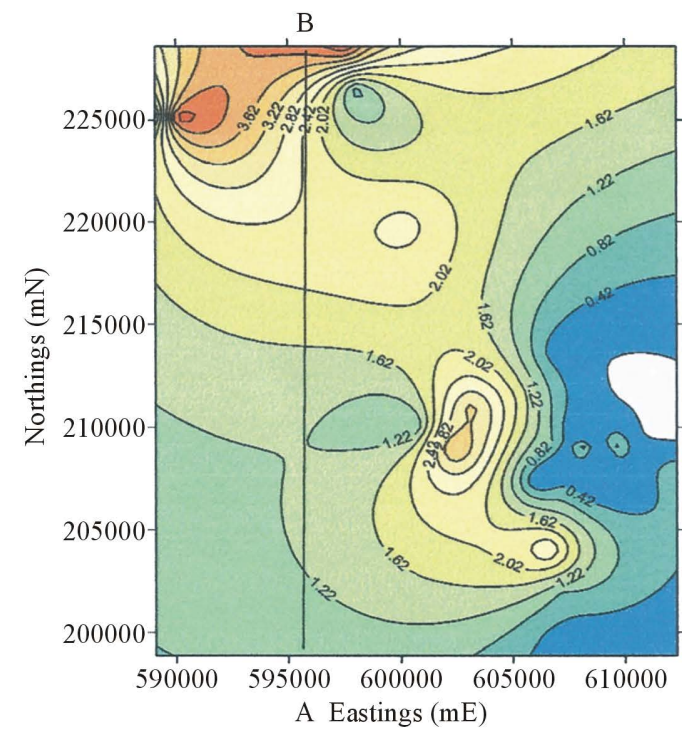

(a)
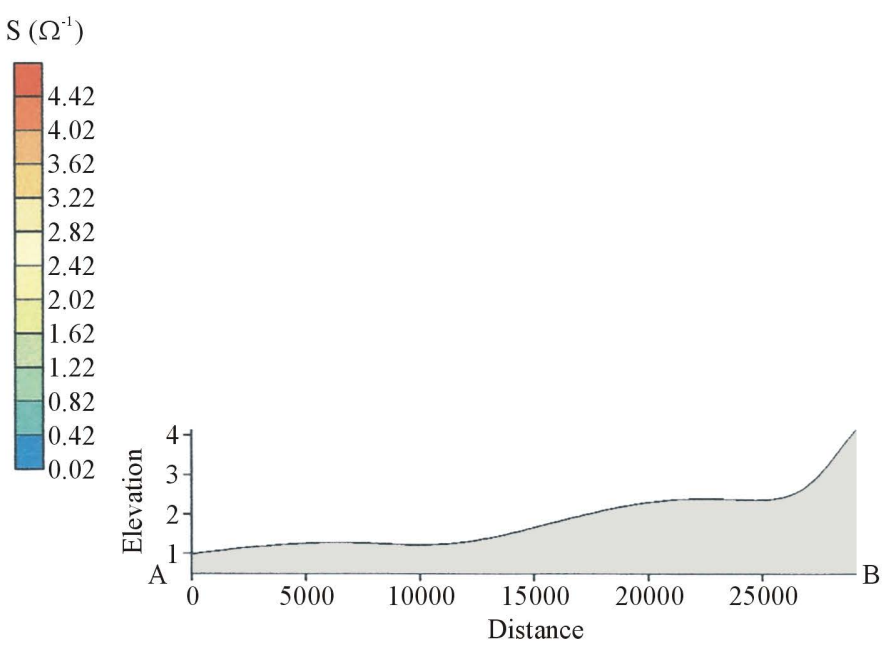

(b)

Figure 10. (a) Longitudinal conductance-S $\left(\Omega^{-1}\right)$ map; (b) Aquifer longitudinal conductance profile. 


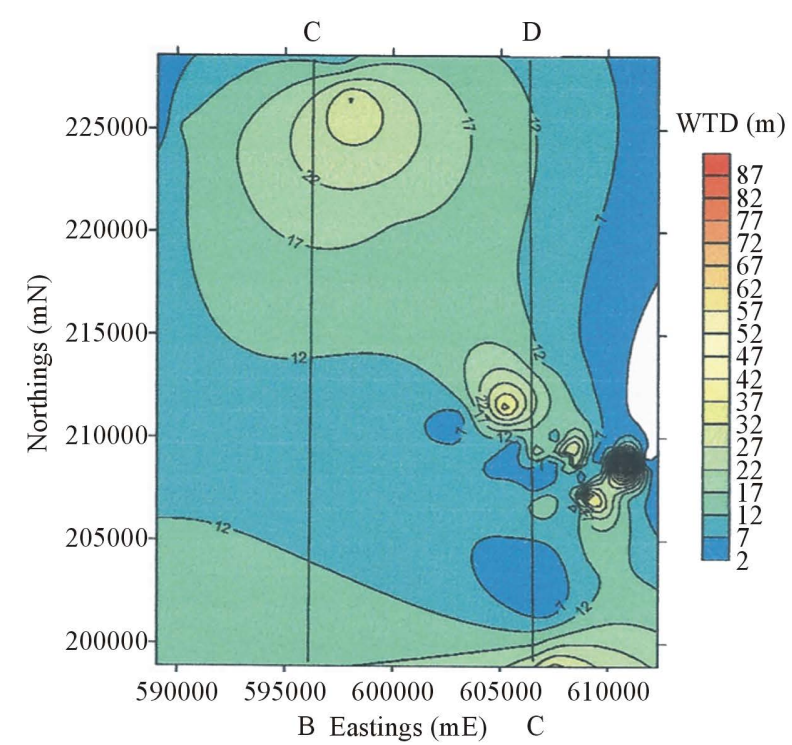

(a)

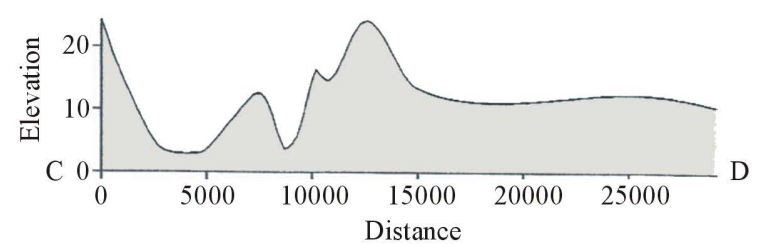

(c)

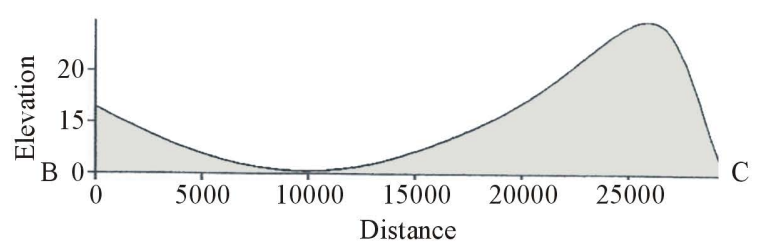

(b)

Figure 11. (a) Water table Depth-WTD (m) contour map; (b) Water table Depth-profile (B-C); (c) Water table Depth-profile (C-D).

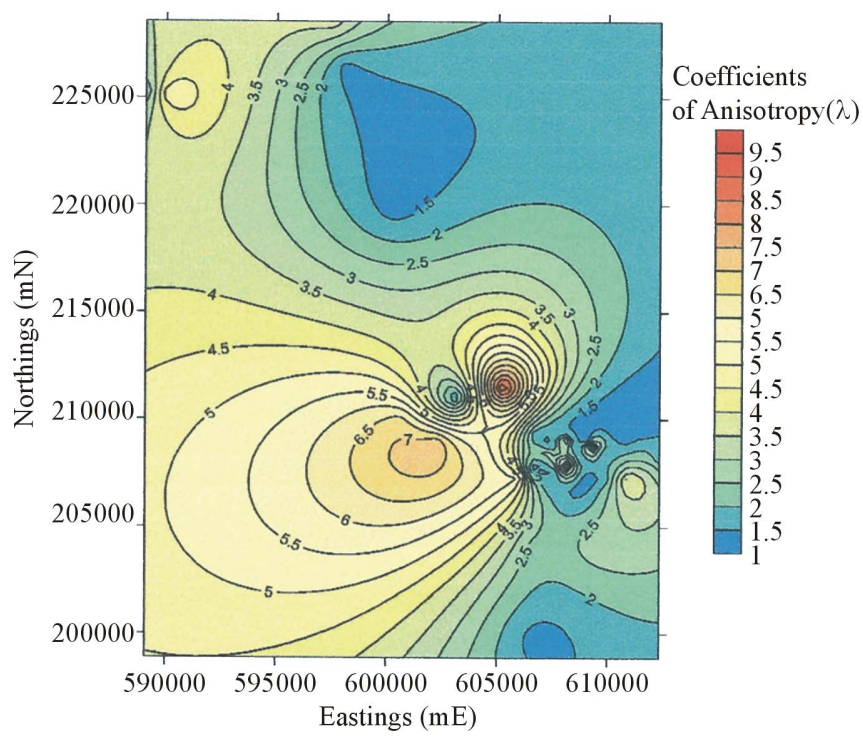

Figure 12. Contour map showing the distribution of coefficients of anisotropy.

\section{Acknowledgements}

Our recognition and gratitude go to Groundscan Services Nigeria Limited for the immeasurable support in providing the Resistivity Meter (ABEM SAS-1000) used for depth probes and some personnel for field assistance in the data collection stage of this work. Several other persons merit our gratefulness. The efforts of Oyim Oko; a practicing geologist of Koyim Consults Nigeria Limited who helped in preparing the borehole lithologic data deserve our appreciation. We are also deeply indebted to all authors whose works we consulted in course of this work.

\section{References}

[1] Ahmed, S. and Marsily, G. (1987) Comparison of Geostatistical Methods for Estimating Transmissivity Using Data on 
Transmissivity and Specific Capacity. Water Resources Research, 23, 1717-1738. http://dx.doi.org/10.1029/WR023i009p01717

[2] Batte, A.G., Muwanga, A. and Sigrist, W.P. (2008) Evaluating the Use of Vertical Electrical Sounding as a Groundwater Exploration Technique to Improve on the Certainty of Borehole Yield in Kamuli District (Eastern Uganda). African Journal Science Technology, 9, 72-85.

[3] George, N.J., Obianwu, V.I. and Obot, I.B. (2011) Estimation of Groundwater Reserve in Unconfined Frequently Exploited Depths of Aquifer Using a Combined Surficial Geophysical and Laboratory Techniques in the Niger Delta South-South, Nigeria. Advances in Applied Science Research, 2, 163-177.

[4] Ugada, U., Okpara, A.I., Emberga, T.T., Ibim, F.D., Omenikoro, A.I. and Womuru, E.N. (2013) Delineation of Shallow Aquifers of Umuahia and Environs, Imo River Basin, Nigeria, Using Geo-Sounding Data. Journal of Water Resource and Protection, 5, 1097-1109. http://dx.doi.org/10.4236/jwarp.2013.511115

[5] Teikeu, W.A., Njandjock, P.N., Bisso, D. and Atangana, Q.Y. (2012) Hydrogeophysical Parameters Estimation for Aquifer Characterization in Hard Rock Environment: A Case Study from Yaounde, Cameroon. Journal of Water Recourses and Protection, 4, 944-953. http://dx.doi.org/10.4236/jwarp.2012.411110

[6] Kelly, W.E. (1977) Geoelectrical Sounding for Estimating Hydraulic Conductivity. Ground Water, 15, 420-425. http://dx.doi.org/10.1111/j.1745-6584.1977.tb03189.x

[7] Niwas, S. and Singhal, D.C. (1981) Estimation of Aquifer Transmissivity from Dar Zarrouk Parameters in Porous Media. Journal of Hydrology, 50, 393-399. http://dx.doi.org/10.1016/0022-1694(81)90082-2

[8] Niwas, S. and Singhal, D.C. (1985) Aquifer Transmissivity of Porous Media from Resistivity Data. Journal of Hydrology, 82, 143-153. http://dx.doi.org/10.1016/0022-1694(85)90050-2

[9] Keller, G.V. and Frischknecst, F.C. (1966) Electrical Methods in Geophysical Prospecting. Pergamon Press, London.

[10] Niwas, S. and de Lima, O.A.L. (2003) Aquifer Parameter Estimation from Surface Resistivity Data. Groundwater, 41, 94-99. http://dx.doi.org/10.1111/j.1745-6584.2003.tb02572.x

[11] Aweto, K.E. and Akpoborie, I.A. (2015) Estimating Aquifer Parameters with Geoelectric Soundings: Case Study from the Shallow Benin Formation at Orerokpe, Western Niger Delta, Nigeria. British Journal of Applied Science \& Technology, 6, 486-496. http://dx.doi.org/10.9734/BJAST/2015/14541

[12] Reyment, R.A. (1969) Aspects of Geology of Nigeria. Ibadan University Press, Ibadan.

[13] Okereke, C.O. (2012) Sedimentology and Facies Analysis of Amasiri Sandstone, Lower Benue Trough, South Eastern Nigeria. Master's Thesis, Nnamdi Azikiwe University, Awka.

[14] Okonkwo, A.C., Okeke, P.O. and Opara, A.I. (2013) Evaluation of Self-Potential Anomalies over Sulphide Ore Deposits at Ishiagu, Ebonyi State, Southeastern Nigeria. International Research Journal of Geology and Mining, 4, 9-19.

[15] Obiora, S.C. (2002) Evaluation of the Effects of Igneous Bodies on the Sedimentary Fills of the Lower Benue Rift and Vice Versa. Unpublished PhD Thesis, University of Nigeria, Nsukka.

[16] Simpson, A. (1954) The Nigerian Coal Field: The Geology of Parts of Onitsha, Owerri and Benue Provinces. Geological Survey Nigerian Bulletin, 24, 1-67.

[17] Reyment, R.A. (1965) Aspects of Geology of Nigeria. Ibadan University Press, Ibadan.

[18] Whiteman, A. (1982) Nigeria: Its Petroleum Geology, Resources and Potential. Graham and Trotham, London.

[19] Simpson, A. (1955) The Nigeria Coalfield: The Geology of Parts of Onitsha, Owerri and Benue Provinces. Geology, 103, 385-397.

[20] Lashkaripour, G.R. (2003) An Investigation of Groundwater Condition by Geoelectrical Resistivity Method in Korin Aquifer, Southeast Iran. Journal of Spatial Hydrology, 3, 1-5.

[21] El Osita, M.M., El Sheikh, A.E. and Barseem, M.S. (2010) Comparative Hydrological and Geoelectrical Study on the Quarternary Aquifer in the Deltas of Wadi Badaa and Ghweiba, El Ain El Sukhna Area, Northwest Suez Gulf, Egypt. International Journal of Geophysics, 20, 15-43.

[22] Zohdy, A.A.R. (1989) A New Method for the Automatic Interpretation of Schlumberger and Wenner Sounding Curves. Geophysics, 54, 245-253. http://dx.doi.org/10.1190/1.1442648

[23] Iduma, R.E.O. (2014) Geostatistical Modeling of Groundwater Aquifer in Parts of Afikpo and Ohaozara Southeastern Nigeria. Unpublished Doctoral Thesis, Rivers State University of Science and Technology, Port-Harcourt.

[24] Zohdy, A.A.R. (1974) Use of Dar-Zarrouk Curves in the Interpretation of Vertical Electrical Sounding Data. United States Geological Survey Bulletin, 1313, 41.

[25] Watson, K.A. and Barker, R.D. (1999) Differentiating Anisotropy and Lateral Effects Using Azimuthal Resistivity Offset Wenner Soundings. Geophysics, 64, 739-745. http://dx.doi.org/10.1190/1.1444583 
[26] Christensen, N.B. (2000) Difficulties in Determining Electrical Anisotropy in Subsurface Investigation. Geophysical Prospecting, 48, 1-19. http://dx.doi.org/10.1046/j.1365-2478.2000.00174.x

[27] Hubbert, M.K. (1940) Theory of Groundwater Motion. Journal of Geology, 48, 785-944. http://dx.doi.org/10.1086/624930

[28] Fitts, C.R. (2002) Groundwater Science. Elsevier Scientific Publishers, Amsterdam.

[29] Viessman Jr., W. and Lewis, G. (2002) Introduction to Hydrology. Pearson Education Inc., Upper Saddle River.

[30] Yalo, N., d’Almeida, G.F., Dovonou, F., Lawin, A.E. and Gnammi, Y.I.R.D. (2013) Estimation of an Unconfined Sandy Aquifer Parameters Using Gravimetric and Geoelectrical Methods. International Research Journal of Geology and Mining, 4, 20-28.

[31] Schwarz, S.D. (1988) Application of Geophysical Methods to Groundwater Exploration in the Tolt River Basin, Washington State. Geotechnical and Environmental Geophysics, 1, 213-217. http://dx.doi.org/10.4133/1.2921817

[32] Archie, G.E. (1942) The Electrical Resistivity Log as an Aid in Determining Some Reservoir Characteristics. Transactions of the AIME, 146, 54-62. http://dx.doi.org/10.2118/942054-g

[33] Telford, W.M., Geldart, L.P., Sheriff, R.E. and Keys, D.A. (1976) Applied Geophysics. Cambridge University Press, Cambridge.

[34] Frohlich, R.K. and Parke, C.D. (1989) The Electrical Resistivity of the Vadose Zone Field Study. Groundwater, 25, 525-530.

[35] Hoover, D.B., Reran, W.D. and Hill, P.L. (1992) The Geophysical Expression of Selected Mineral Deposit Models. Report No. 92-557, US Geological Survey, Reston.

[36] Grant, F.S. and West, G.F. (1965) Interpretation Theory in Applied Geophysics. McGraw-Hill, New York.

[37] Mazac, O.M., Kelly, W.E. and Landa, I. (1985) A Hydrogeophysical Model for Relations between Electrical and Hydraulic Properties of Aquifers. Journal of Hydrology, 79, 1-19. http://dx.doi.org/10.1016/0022-1694(85)90178-7

[38] Obasi, P.N.I. and Akudinobi, B.E.B. (2013) Hydrochemical Evaluation of Water Resources of the Ohaozara Areas of Ebonyi State, Southeastern Nigeria. Journal of Natural Sciences Research, 3, 75-80.

[39] Hesse, H.W. and McDonald, R.L. (1975) The Earth and Its Environment. Dickenson Press, New York.

[40] Habberjam, G.M. and Watkins, G.E. (1967) The Use of a Square Configuration in Resistivity Prospecting. Geophysical Prospecting, 15, 445-467. http://dx.doi.org/10.1111/j.1365-2478.1967.tb01798.x 